\title{
Magnetic Response of Amorphous and Nanocrystalline FeSn(P)B Ribbons to Electron Irradiation
}

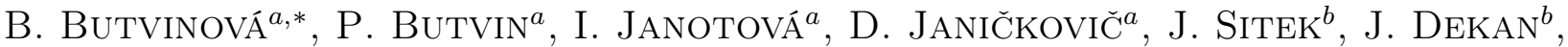 \\ D. HOLKOVÁ ${ }^{b}$ AND I. MAŤKO ${ }^{a}$ \\ ${ }^{a}$ Institute of Physics Slovak Academy of Sciences, Dúbravská cesta 9, 84511 Bratislava, Slovakia \\ ${ }^{b}$ Institute of Nuclear and Physical Engineering, Faculty of Electrical Engineering and Information Technology, \\ Slovak University of Technology, Ilkovičova 3, 81219 Bratislava, Slovakia
}

\begin{abstract}
Metallic glass ribbons of composition $\mathrm{Fe}_{83}(\mathrm{Sn} / \mathrm{P})_{5} \mathrm{~B}_{12}$ with or without $2 \%$ phosphorus substitution were irradiated with a $5 \mathrm{MeV}$ electron beam, and $4 \mathrm{MGy}$ dose. We examined the effect of irradiation on magnetic properties in amorphous sample, and its result in nanocrystallized sample. Both irradiated and non-irradiated samples were annealed at $400{ }^{\circ} \mathrm{C}$ for $1 / 2 \mathrm{~h}$ in vacuum to obtain the nanocrystalline phase. The P-containing ribbon is better in terms of magnetic softness but the saturation induction is reduced by $2.5 \%$. Both the materials show merely minute effects of the irradiation after nanocrystallization.
\end{abstract}

DOI: 10.12693/APhysPolA.137.839

PACS/topics: electron irradiation, hysteresis loop, nanocrystalline alloys

\section{Introduction}

Rapidly quenched (RQ) soft-magnetic alloys containing small metalloid addition are permanently of great interest for the industry, as well as for the modern material research. Various alloys as $\mathrm{NiFe}$ and $\mathrm{NiCoFe}$ or nuclear reactor vessel steels show magnetic hardening and/or segregation of defect clusters, and structural changes after particle bombardment [1-3]. Such changes in microstructure and the damage behavior due to exposure to various kinds of radiation, were widely investigated on RQ materials $[4,5]$. Whereas bombardment with relatively massive neutrons clearly causes changes, properly considered as "damage", the electron irradiation has proved to be an efficient way as well to realize "finer" structural changes of the amorphous or crystalline phase $[6,7]$. Effects of the electron irradiation were studied on new nanocrystalline alloys NANOMET $(\mathrm{FeCo}(\mathrm{Cu}) \mathrm{BP})$, and has been found to affect the crystallization transformation which is an important factor to obtain the soft magnetic behavior [8].

Alloys of $\mathrm{Fe}-\mathrm{Cu}-\mathrm{Si}-\mathrm{B}$ with a small amount of $\mathrm{P}$ added (changing $\mathrm{Fe}$ or Si percentage) were investigated, and their very good soft magnetic properties with high saturation induction were obtained [9]. Composition Fe-Sn-B is known only a few years ago showing up very good combination of structural and magnetic properties [10]. This motivated us to investigate, if and how, the electron irradiation can influence the structure and magnetic properties of this less known but promising material.

*corresponding author; e-mail: beata.butvinova@savba.sk

\section{Experimental details}

Alloys of $\mathrm{Fe}_{83} \mathrm{Sn}_{5-y} \mathrm{P}_{y} \mathrm{~B}_{12}(y=0 ; 2$ at.\%) without and with substitution of $\mathrm{P}$ for Sn, were prepared by planar flow casting method in air. As-cast ribbons were about $22 \mu \mathrm{m}$ thick, and $7 \mathrm{~mm}$ wide. Amorphous structure has been verified by X-ray diffraction (XRD) with the $\mathrm{CuK} \alpha$ radiation. Samples were checked by Differential Scanning Calorimetry (DSC) to estimate the critical temperatures. Energy Dispersive Spectroscopy (EDS) was used to check the composition. Since buoyancy method to determine the density was problematic due to small sample volume, its thickness was verified by electron microscopy. Thermo-gravimetric Analysis (TGA) has been used to find out the Curie temperature $T_{\mathrm{C}}$. Electron irradiation of amorphous precursor was performed at SMU Trenčín using a linear accelerator with a dose up to 4 MGy with electron energy $5 \mathrm{MeV}$. The applied dose density of irradiation corresponds to $1.746 \times 10^{16} \mathrm{e} / \mathrm{cm}^{2}$. Annealing was carried out in vacuum furnace at the temperature of $400{ }^{\circ} \mathrm{C}$ for $30 \mathrm{~min}$. Mössbauer spectra (MS) were measured in transmission geometry on a standard constant acceleration spectrometer with a source of ${ }^{57} \mathrm{Co}(\mathrm{Rh})$. All spectra were recorded at room temperature and evaluated using the CONFIT program [7], allowing simultaneous treatment of crystalline components and residual amorphous phases using individual lines and distributions of hyperfine parameters. Magnetic properties were determined by measurements of hysteresis loops on open samples. Hysteresis loops were recorded using a digitizing hysteresisgraph at standard ac (frequency $21 \mathrm{~Hz}$ ) sinusoidal $\mathrm{H}$ excitation in Helmholtz drive coils in longitudinal direction on $10 \mathrm{~cm}$ long strips. In order that the loops do not reflect particular sample geometry, demagnetization effect was subtracted using standard 
formula $H_{\mathrm{i}}=H_{\text {ext }}-\frac{D J}{\mu_{0}}$ where $H_{\mathrm{i}}$ is the internal, $H_{\text {ext }}$ is the external excitation field, and $D$ (of the order $10^{-5}$ ) is the geometric demagnetization factor evaluated using elliptic integrals.

\section{Results and discussion}

As-quenched ribbons with the typical shiny air side and matt wheel side showed no sign of crystallinity on their surfaces either. Two phase transformations were observed by DSC for both the alloys, whereas P-containing sample has shown a considerable shift of first and second transformation to higher temperature, as seen in Fig. 1. This is similar to $\mathrm{FeCoSiB}(\mathrm{P})$ alloys, where due to $\mathrm{P}$ contents, higher annealing temperature was prompted to attain nanocrystallization, and so the annealing resulted in slightly different alloy microstructure [11].

TGA measurements point to the lower Curie temperature of the amorphous phase for the $\mathrm{P}$-containing alloy (i.e., $T_{\mathrm{C}}=335^{\circ} \mathrm{C}$, while $T_{\mathrm{C}}=349^{\circ} \mathrm{C}$ for P-free alloy). The curves are shown in Fig.2. When partly crystallized, $T_{\mathrm{C}}$ of both alloys rise, but now $T_{\mathrm{C}}$ for the $\mathrm{P}$-free alloy is lower $\left(T_{\text {Can }}=481^{\circ} \mathrm{C}\right.$ for P-free, whereas $T_{\text {Can }}=500^{\circ} \mathrm{C}$ for P-containing alloy), what corresponds well with lower crystallization temperature of the P-free alloy (Fig. 1).

Electron irradiation was reflected in the shape of hysteresis loops (see Fig. 3 and Fig. 4), also in the measured coercivity $H_{c}$ value, and the maximum magnetic polarization $J_{\max }$. The exciting field was not enough to saturate the samples in as-cast state. The magnetic properties evaluated for both samples without and with irradiation can be found in Table I. Amorphous samples showed a relatively low coercivity (i) of $50 \mathrm{~A} / \mathrm{m}$, which after irradiation it dropped to $48 \mathrm{~A} / \mathrm{m}$ for $\mathrm{P}$-free ribbon, and (ii) of $32 \mathrm{~A} / \mathrm{m}$ dropped to $27 \mathrm{~A} / \mathrm{m}$ for P-containing alloy, respectively.

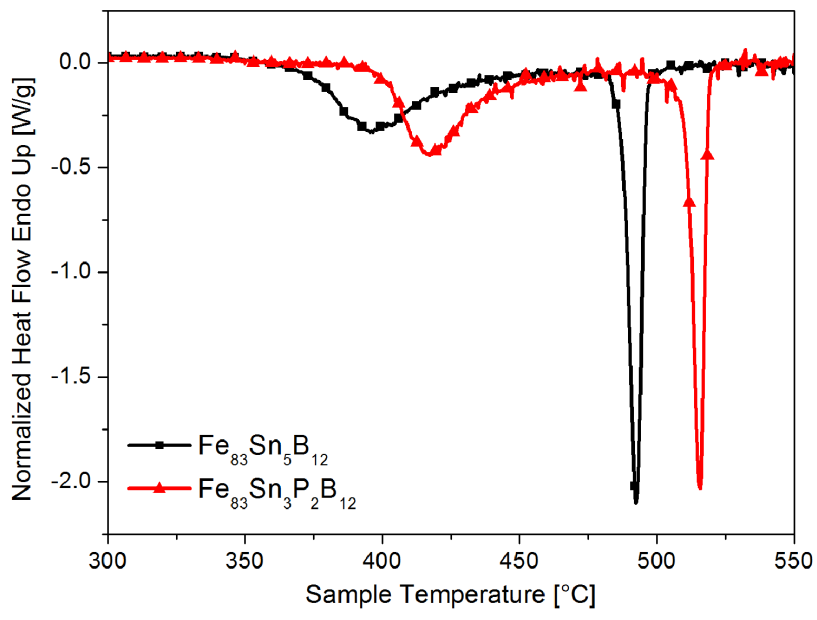

Fig. 1. DSC curves of as-quenched ribbons of $\mathrm{Fe}_{83} \mathrm{Sn}_{5-y} \mathrm{P}_{y} \mathrm{~B}_{12}(y=0 ; 2$ at. $\%)$ measured at $10^{\circ} \mathrm{C} / \mathrm{min}$ in Ar atmosphere.

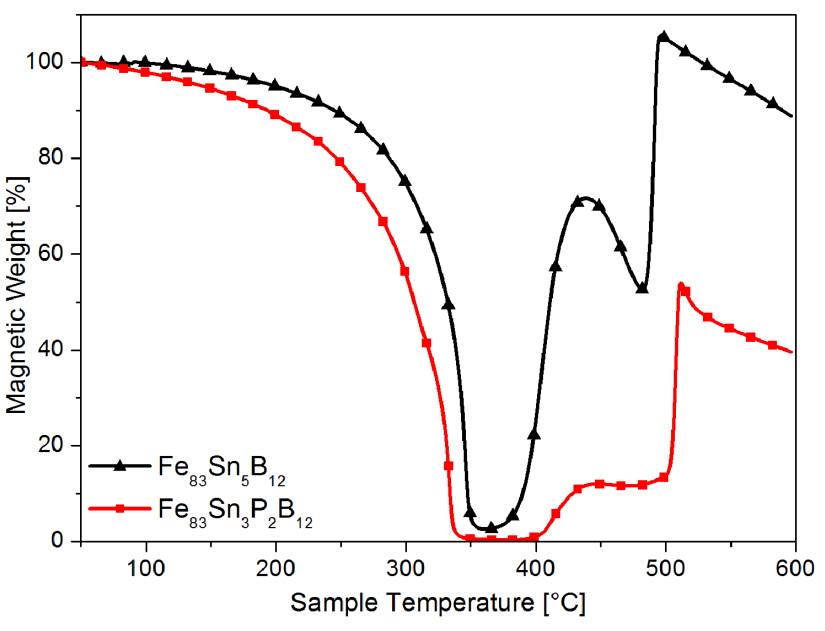

Fig. 2. TGA curves of as-quenched ribbons of $\mathrm{Fe}_{83} \mathrm{Sn}_{5-y} \mathrm{P}_{y} \mathrm{~B}_{12}(y=0 ; 2$ at. $\%)$ measured at $10{ }^{\circ} \mathrm{C} / \mathrm{min}$ in Ar atmosphere.

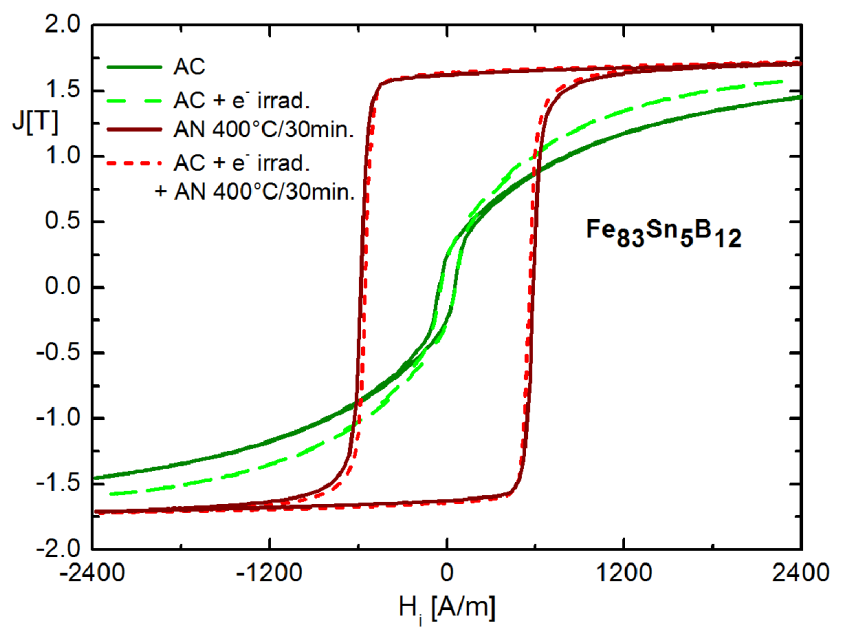

Fig. 3. Hysteresis loops of as-cast (AC), $e^{-}$irradiated and annealed (AN) of $\mathrm{Fe}_{83} \mathrm{Sn}_{5} \mathrm{~B}_{12}$ ribbon.

\section{TABLE I}

Magnetic properties of $\mathrm{Fe}_{83}(\mathrm{SnP})_{5} \mathrm{~B}_{12}$ ribbons. AC stands for "as-cast", irr. denotes electron irradiation by $4 \mathrm{MGy}, 557 \mathrm{~Gy} / \mathrm{s}, 160 \mathrm{~min}$.

\begin{tabular}{l|c|c}
\hline \hline \multicolumn{1}{c|}{ RQ ribbons } & $H_{c}[\mathrm{~A} / \mathrm{m}]$ & $J_{\max }[\mathrm{T}]$ \\
\hline \multicolumn{3}{c}{$\mathrm{Fe}_{83} \mathrm{Sn}_{5} \mathrm{~B}_{12}$} \\
\hline $\mathrm{AC}$ & 50 & 1.45 \\
$\mathrm{AC}+$ irr. & 48 & 1.58 \\
$\mathrm{AC}+$ irr. + annealed & 557 & 1.72 \\
$\mathrm{AC}+$ annealed & 584 & 1.72 \\
\hline \multicolumn{3}{c}{$\mathrm{Fe}_{83} \mathrm{Sn}_{3} \mathrm{P}_{2} \mathrm{~B}_{12}$} \\
\hline $\mathrm{AC}$ & 32 & 1.47 \\
$\mathrm{AC}+$ irr. & 27 & 1.58 \\
$\mathrm{AC}+$ irr. + annealed & 559 & 1.68 \\
$\mathrm{AC}+$ annealed & 552 & 1.70
\end{tabular}


TABLE II

Mössbauer spectroscopy results of $\mathrm{Fe}_{83}(\mathrm{SnP})_{5} \mathrm{~B}_{12}$ ribbons. $A_{23}$ - direction of net magnetic moment, $A_{\mathrm{am}}, A_{\mathrm{cr}}-$ relative amorphous and crystalline area, $B_{\mathrm{am}}, B_{\mathrm{cr}}$-induction of internal magnetic field for amorphous and crystalline component.

\begin{tabular}{|c|c|c|c|c|c|c|c|c|c|c|}
\hline \multirow{2}{*}{ Sample type } & \multicolumn{2}{|c|}{$A_{23}$} & \multicolumn{2}{|c|}{$B_{\text {am }}[\mathrm{T}]$} & \multicolumn{2}{|c|}{$A_{\mathrm{am}}[\%]$} & \multicolumn{2}{|c|}{$B_{\mathrm{cr}}[\mathrm{T}]$} & \multicolumn{2}{|c|}{$A_{\mathrm{cr}}[\%]$} \\
\hline & $\mathrm{Sn}_{5}$ & $\mathrm{Sn}_{3} \mathrm{P}_{2}$ & $\mathrm{Sn}_{5}$ & $\mathrm{Sn}_{3} \mathrm{P}_{2}$ & $\mathrm{Sn}_{5}$ & $\mathrm{Sn}_{3} \mathrm{P}_{2}$ & $\mathrm{Sn}_{5}$ & $\mathrm{Sn}_{3} \mathrm{P}_{2}$ & $\mathrm{Sn}_{5}$ & $\mathrm{Sn}_{3} \mathrm{P}_{2}$ \\
\hline \multirow{2}{*}{ amorphous } & 2.41 & 2.58 & 26.3 & 27.3 & 68 & 35 & & & & \\
\hline & & & 25.4 & 24.4 & 32 & 65 & & & & \\
\hline \multirow{2}{*}{$\begin{array}{l}\text { amorphous } \\
+ \text { irradiated }\end{array}$} & 3.61 & 2.60 & 27.2 & 27.2 & 56 & 22 & & & & \\
\hline & & & 25.3 & 26.3 & 44 & 78 & & & & \\
\hline \multirow{2}{*}{ nanocrystalline } & 1.86 & 2.32 & & & & & 33.1 & 32.3 & 12 & 20 \\
\hline & 1.79 & 2.35 & 24.7 & 25.7 & 88 & 80 & & & & \\
\hline \multirow{2}{*}{$\begin{array}{l}\text { irradiated, } \\
\text { then nanocrystallized }\end{array}$} & 2.29 & 2.75 & & & & & 32.4 & 32.4 & 32 & 32 \\
\hline & 2.31 & 2.35 & 26.4 & 26.4 & 68 & 68 & & & & \\
\hline
\end{tabular}

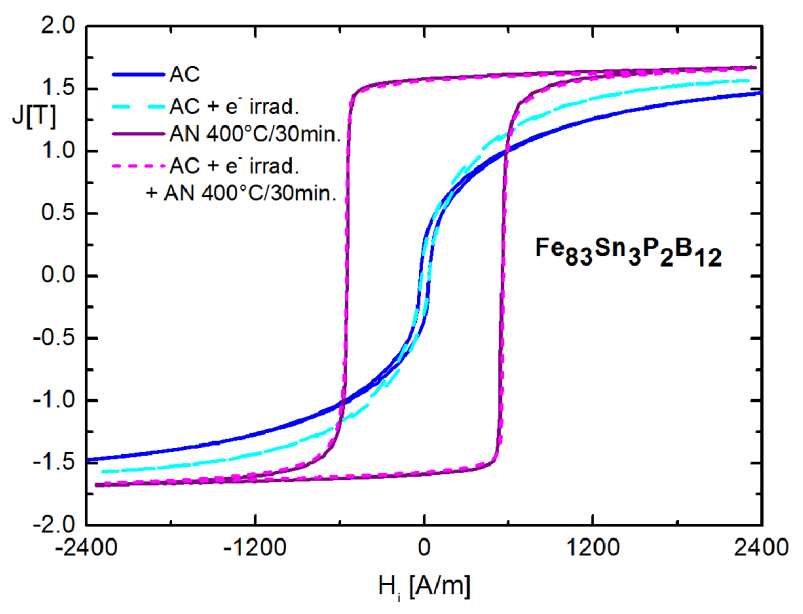

Fig. 4. Hysteresis loops of as-cast (AC), $e^{-}$irradiated and annealed (AN) of $\mathrm{Fe}_{83} \mathrm{Sn}_{3} \mathrm{P}_{2} \mathrm{~B}_{12}$ ribbon.

The shape of the hysteresis loop after irradiation in the amorphous state exhibited a slight reduction of the off-axis anisotropy, and thus a better approach to saturation. Maximal magnetic polarization $J_{\max }$ increases up to $1.58 \mathrm{~T}$ for both the alloys. We attribute this to structural relaxation, some reduction of internal stresses in the ribbons, which is reflected by the decrease in the magnetic anisotropy ("natural" longitudinal anisotropy is better pronounced). Some relaxation could also be enabled by sample heating $\left(<140^{\circ} \mathrm{C}\right)$ during irradiation.

The nanocrystallization is significantly manifested in the loops. Although the coercivity increases more than 10 times after $400^{\circ} \mathrm{C}$ annealing, which is related to the change in microstructure and the formation of medium nano-sized grains ( $~ 35 \mathrm{~nm}$ using Scherrer formula from XRD measurement), approach to saturation markedly improved. As for the saturation itself, the value $J_{\max }=1.72 \mathrm{~T}$ for non-irradiated as well as for irradiated $\mathrm{P}$-free ribbon, whereas for $\mathrm{P}$-containing ribbon $J_{\max }=1.70 \mathrm{~T}$ and $1.68 \mathrm{~T}$ for non-irradiated and irradiated one respectively.
From the results of MS we observed that electron irradiation causes displacement of atoms from their original position. Magnetic interaction contributes to interatomic forces, and therefore the lower internal field of amorphous component becomes more sensitive to electron irradiation than higher internal field (in column $B$, the latter is quoted in the upper part of the undivided lines - see Table II). We assume that some minor reorganization of the original structure and relaxation occur mostly during irradiation.

\section{Conclusions}

$\mathrm{Fe}_{83} \mathrm{Sn}_{5} \mathrm{~B}_{12}$ with 2 at.\% of $\mathrm{P}$ substitution rapidly quenched ribbons were examined for their structural and magnetic properties before and after being exposed to electron irradiation. Just alike previously studied Febased nanocrystalline alloys, the $\mathrm{FeSn}(\mathrm{P}) \mathrm{B}$ alloys studied here show the same effect of $\mathrm{P}$ - namely slowing the crystallization as well. Only minor differences were found in the magnetic properties, especially the amorphous strips with $\mathrm{P}$ had slightly better soft magnetic properties. Irradiation of amorphous ribbons caused better saturation apparently due to minor atoms rearrangement and some release of internal stresses. These minor effects hardly persist in nanocrystallized $\mathrm{FeSn}(\mathrm{P}) \mathrm{B}$ alloys, thus electron irradiation of as-cast alloys does neither significantly deteriorate, nor give actual chance to improve soft magnetic properties for these alloys when nanocrystallized.

\section{Acknowledgments}

Partial financial support of the projects Stimuli HEES4T, APVV-15-0621, VEGA 2/0082/17, VEGA2/0152/16, 1/0064/18 and 1/0477/16 is gratefully acknowledged. The authors would like to thank for irradiation of the samples at the University center of electron accelerator SMU in Trenčín. 


\section{References}

[1] S. Kobayashi, T. Yamamoto, D. Klingensmith, G.R. Odette, H. Kikuchi, Y. Kamada, J. Nucl. Mater. 422, 158 (2012).

[2] Ch. Lu, T. Yang, Ke Jin, N. Gao, P. Xiu, Y. Zhang, F. Gao, H. Bei, W.J. Weber, K. Sun, Y. Dong, L. Wang, Acta Mater. 127, 98 (2017).

[3] K. Jin, C. Lu, L.M. Wang, J. Qu, W.J. Weber, Y. Zhang, H. Bei, Scr. Mater. 119, 65 (2016).

[4] M. Matsushita, S. Akamatsu, Y. Matsushima, A. Iwase, Nucl. Instrum. Methods Phys. Res. B 314, 103 (2013).

[5] S.N. Kane, M. Satalkar, A. Ghosh et al., J. Alloy. Compd. 615, S324 (2014).
[6] T. Nagase, Y. Umakoshi, N. Sumida, Mater. Sci. Eng. A323, 218 (2002).

[7] J. Sitek, D. Holková, P. Novák, J. Dekan, Acta Phys. Pol. A 131(4), 708 (2017).

[8] J. Sitek, D. Holková, J. Dekan, P. Novák, A. Šagátová, S. Soják, AIP Conf. Proc. Appl. Phys. Conden. Matter 1996, 020003 (2018).

[9] B.Butvinová, P. Butvin, I. Mat’ko, D. Janičkovič, M. Kuzminski, A. Slawska-Waniewska, P. Svec Sr., M. Chromčíková, Acta Phys. Pol. A 131, 711 (2017).

[10] I. Janotová, P. Švec Sr., I. Mat'ko, P. Švec, D. Janičkovič, J. Zigo, J. Elec. Engn. 66, 297 (2015).

[11] I. Janotová, J. Zigo, P. Švec, I. Mat'ko, D. Janičkovič, P. Švec Sr., J. Alloys Compd. 643, S265 (2015). 